\title{
Cloud Computing Framework for E-Health in Ghana: Adoption Issues and Strategies: Case Study Of Ghana Health Service
}

\author{
Adu Adolph Sedem \\ Yaw \\ Gcom Pre-University \\ College, Ho, Ghana
}

\author{
Frimpong Twum \\ (Corresponding author) \\ Department Of Computer \\ Science \\ Kwame Nkrumah University \\ of Science and Technology, \\ Kumasi, Ghana
}

\author{
J. B. Hayfron- \\ Acquah, PhD \\ Department Of Computer \\ Science \\ Kwame Nkrumah \\ University of Science and \\ Technology, Kumasi,
}

Ghana.

\author{
Joseph K. Panford \\ Department Of \\ Computer Science \\ Kwame Nkrumah \\ University of Science \\ and Technology, \\ Kumasi, Ghana.
}

\begin{abstract}
Healthcare professionals do not always have all the information they require and at the time when it is most needed to make rapid patient-care decisions. Also healthcare services are still being provided using manual tools and technologies. The adoption of current technologies such as Cloud Computing provides an avenue to overcome these challenges. This paper therefore measures the ICT awareness of stakeholders in healthcare while also providing an evidence of the possibility of cloud implementation by Ghana Health Services (GHS) in relation to the ICT awareness of stakeholders. It also provides a framework for a cloud based E-Health adoption by the GHS
\end{abstract}

\section{General Terms}

Cloud computing, E-Health, Adoption Issues and Strategies, Cloud technologies, cloud service models, cloud deployment models.

\section{Keywords}

Cloud computing, E-Health, Adoption Issues and Strategies, Adoption Framework, Ghana Health Service, GHS.

\section{INTRODUCTION}

GHS, the principal healthcare provider has implemented a number of policies aimed at improving healthcare delivery and access. These policies have not yielded the expected results due to lack of accurate and timely data. A patient's medical information is kept at facilities he/she visits for treatment while their previous history is kept at facilities they visited previously. Healthcare services are still being provided traditionally using paper and pen and other manual technologies. These paper based records contain too many errors and inefficiencies hindering effective communication between health care providers and patients [1]. The Institute of Medicine (IOM) has been advocating for the use of computerized patient records since the early 1990's [2]. In their report, To Err is human: Building a Safer Health System, the committee reported that as many as 98,000 patients die each year from preventable medical errors. With the implementation of Cloud computing in e-Health, healthcare professionals across the globe can collaborate in real time and share patients' medical information. A central repository for patient information will mitigate the risks of misdiagnosis or the prescription of the wrong medication, as well as eliminating chances of conflicting treatments where multiple healthcare providers are involved. Cloud adoption fits very nicely with increasingly mobile healthcare professionals who may need to administer service from remote locations.

\subsection{E-Health}

E-Health is the use of information technologies across healthrelated functions and activities [3]. Studies about e-Health and its successful implementation are being undertaken in both developed and developing countries [4]. Healthcare institutions are developing E-Health systems because traditional medical records are inadequate, inefficient and ineffective in meeting the requirements of modern medicine practice. The adoption of e-Health has several benefits to physicians, patients, management and other departments [5].

\subsection{Cloud Computing}

The motivation to improving the level of modern records management by using innovative technologies has dramatically increased. One of these promising technology is cloud computing and is defined as "Clouds are a large pool of easily usable and accessible virtualized resources (such as hardware, development platforms and/or services) [6].

\subsection{Cloud Computing in Healthcare}

Cloud technologies can be implemented in healthcare as a way for maintaining or managing patient information, monitoring patients' progress, managing diseases and disease surveillance more efficiently and effectively, while helping professionals to collaborate with colleagues at different locations [7]. Cloud adoption also provides the ability to exchange data between disparate and separate systems. Also Cloud computing can be used in educating healthcare professionals in providing access to medical knowledge, applications and literature, while serving as a source for public and formal education for health [8]. There exist research literatures to support the viability of Cloud adoption in e-Health for underdeveloped countries with such studies showing the feasibility of implementing these systems in healthcare delivery [9]. Rolim et al., [10] designed a cloud 
computing platform in Brazil that is used to collect patients' crucial information automatically from legacy medical systems through a network of sensors, and then transfer such data through cloud to a central storage where processing and distributing is done. Furthermore, Koufi et al., [11] proposed a cloud based emergency medical system for the Greek National Health Service which embedded the emergency system with personal health record to offer healthcare providers easy and direct access to patient medical data from anywhere in the world and at any time at the lowest cost using any computer device. An example of a cloud based e-health model is as shown in figure 1 . This system helps healthcare institutions to improve patient care while reducing cost and increasing system efficiency [12].

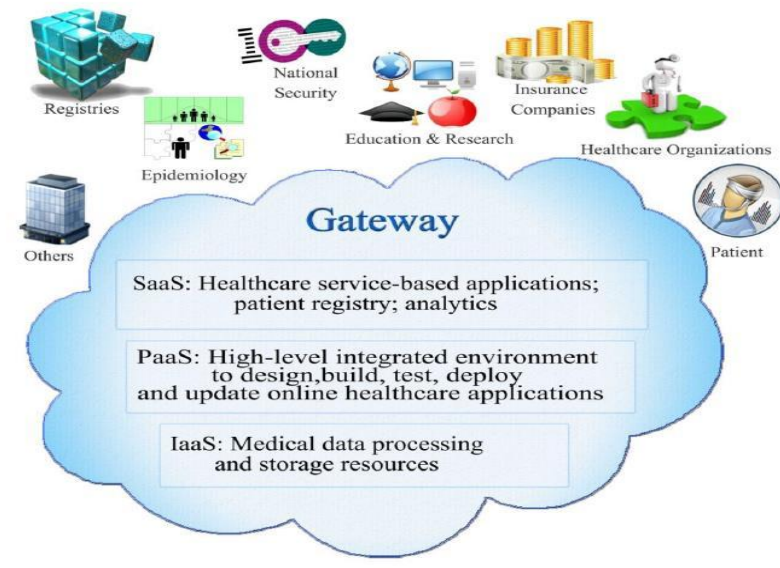

Figure 1: E-health cloud model [12]

\subsection{Benefits of Cloud Computing in Healthcare}

Cloud implementation in healthcare offers the potential of quick access to electronic medical records (EMR) and to a patient's medical history, in effect this fastens the treatment of patients, helping to avoid medical complications, and even saving patient lives [13]. Also cloud computing adoption makes it much easier for patients and healthcare institutions to locate and keep track of their own medical history while facilitating medical information resource sharing among healthcare providers. Clouds allows users or organizations to have the right to access medical records online, to engage their providers via digital channels, and to share their records across teams of healthcare professionals [14]. Cloud computing also helps to provide rapid access to the electronic medical records of patients especially in Emergency situations by providing important information about a patient's medical history and current description of medications [13]. Current trends aim towards accessing information anytime, anywhere and this can be achieved by moving healthcare information to the cloud. Most healthcare institutions are now shifting the burden of managing and maintaining complex HIT to the Cloud service providers [15].

\subsection{Theoretical Framework}

This study is interested in the Diffusion of Innovation theory because it is one of the few adoption theories that focus on technology adoption at the level of the organization. The TAM, TPB and UTAUT adoption theories are used at the individual level.

\subsubsection{Diffusion of Innovation (DOI) Theory}

Diffusion is the process by which i) an innovation ii) is communicated through certain channels iii) over time iv) among the members of a social system. Diffusion is a special type of communication concerned with the spread of messages that are perceived as new ideas. The characteristics of an innovation, as perceived by the members of a social system, determine its rate of adoption. So the rate of adoption is a numerical indicator of the steepness of the adoption curve for an innovation. DOI deals with how, why, and at what rate emerging ideas coupled with technology can spread through cultures, operating at the individual and firm level. Individuals are seen as possessing different degrees of willingness to adopt innovations, and thus it is generally observed that the portion of the population adopting an innovation is approximately normally distributed over time [16]. The normal distribution can be used to group individuals into the following five categories of individual innovativeness (from earliest to latest adopters): innovators, early adopters, early majority, late majority, laggards [16]. The innovation process in organizations is much more complex. It generally involves a number of individuals, perhaps including both supporters and opponents of the new idea, each of whom plays a role in the innovation-decision. Based on DOI theory at firm level [16], innovativeness is related to such independent variables as individual (leader) characteristics, internal organizational structural characteristics, and external characteristics of the organization.

\section{METHOD}

A cross sectional survey was adopted for this research. This form of research provides a comprehensive enquiry into part of a subject with similar attributes to the entire subject under study to obtain an understanding of the whole subject. It was adopted more so because of the similar operational environment and style of health care delivery across Ghana. Cluster sampling technique was used to sample the various participants for the research. A total of 260 participants ( 142 males and 118 females) took part in the research out of which 200 were stakeholders from the healthcare industry while the remaining 60 were experts in cloud computing. Of the 200 stakeholders in healthcare 46 were Doctors, 51 were Nurses, 78 were Patients while Administrative staffs of the GHS at the various hospitals were 25. The data collection tool used was the questionnaires and participants indicated their opinion by ticking a number from one to five, on a Likert scale with responses ranging between strongly disagree and strongly agree. Tests of significance and correlation were performed with the help of SPSS.

\section{RESULTS AND DISCUSSIONS 3.1 Measuring the Extent to Which Stakeholders are IT Inclined}

In general most respondents' response regarding their awareness and use of Information and Communication technology (ICT) varied mostly between Strongly Agree and Agree (see Table 1) suggesting most stakeholders in healthcare are ICT inclined $(\mathrm{p}<0.05)$.

\subsection{Possibility of Implementing Cloud Computing by GHS}

Results of Test statistics (T-test) conducted appears to suggest that stakeholders believe there is a possibility of implementing cloud computing in the healthcare for the efficient delivery of health services in Ghana ( $<0.05)$ - see Table 2. Therefore a cloud based e-health for GHS may create an avenue for 
increased access to healthcare data regardless of patient or healthcare facility's location. This, in Ghana it might be useful to smaller hospitals, clinics, community health centers and CHIPS compounds.

\subsection{Evaluation of Cloud Model suitable for Adoption by GHS}

Analysis carried out appears to suggest there is a significant correlation between the cloud customer view of the safety of data outsourced to the cloud, the effects of cloud computing on healthcare (i.e. improved healthcare ) and GHS adoption of cloud computing. In addition, the result suggests Hybrid cloud model would be the best for GHS adoption. Although it also appears any cloud model may be deployed by GHS - see Table 2 .

\section{CONCLUSIONS}

Within the framework for a Cloud Based E-Health for GHS a stakeholder in healthcare including Doctors, Nurses and Physicians gain access to the GHS Private cloud through the cloud infrastructure of a particular Cloud Service Provider (CSP) and are able to view information such as the medical history of their patients before attending to them. Patients and staffs of GHS and the various hospitals are also able to use mobile devices to gain access to the GHS private cloud. Different access control levels such as Private, Community and Public levels are proposed for accessing different resources (i.e. the different types of healthcare services being rendered by GHS) within the GHS private cloud service model safely by the CSP. It was realized from the study that most of the stakeholders such as Doctors, Nurses, Hospital staff and Patients in the Health care industry are Information technology inclined. The study also revealed that stakeholders believed there is a possibility of implementing cloud computing for the GHS and that Hybrid model will be most suitable though any model deployed may be appropriate. The study therefore proposes the cloud computing framework as shown in figure 2 . Future work could take a look at security issues and security implementation strategies of cloud computing for e-Health.

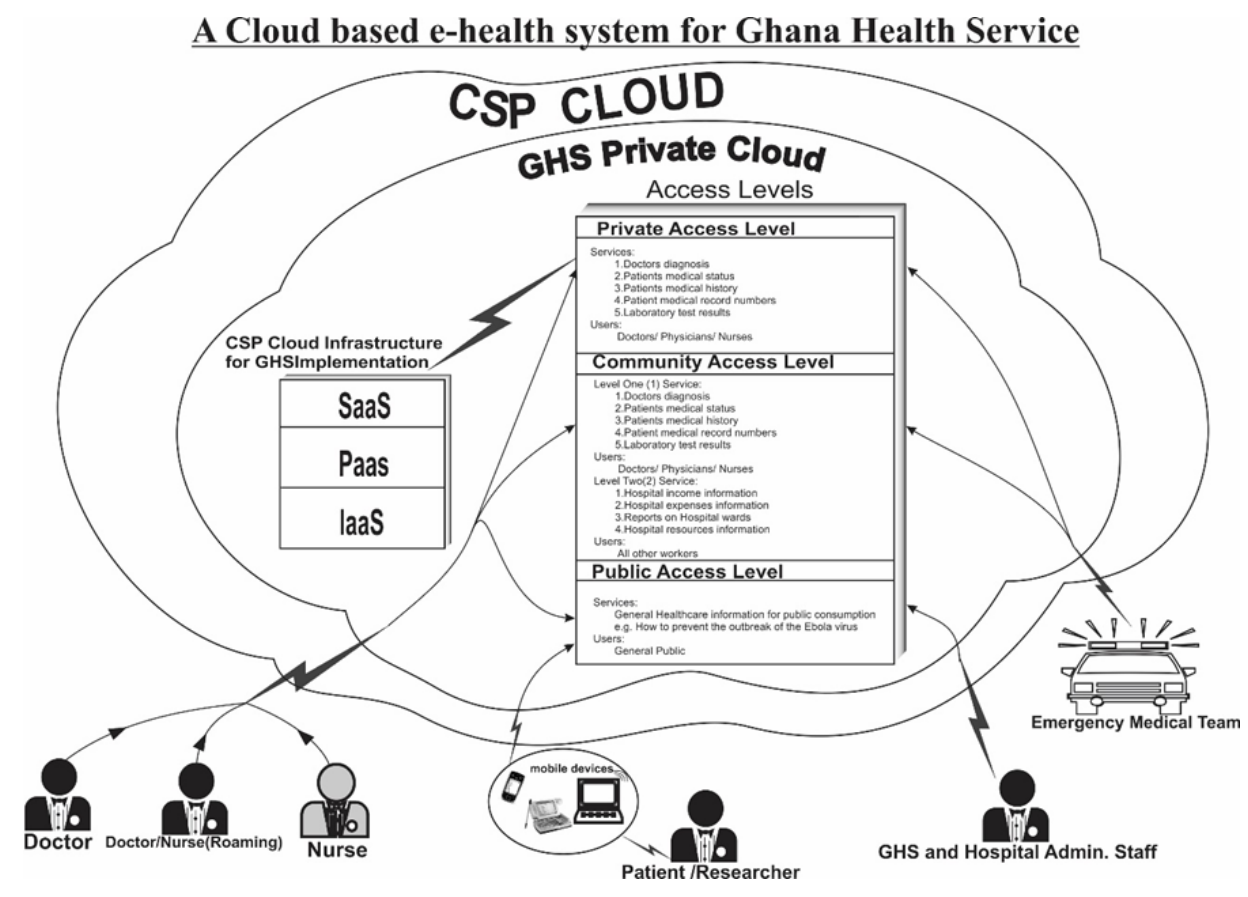

Figure 2: Cloud based Framework for GHS. Source: Authors construct 2014 


\section{REFERENCES}

[1] Mullner, R. M., \& Chung, K. (2006). Current issues in health care informatics. Journal of Medical Systems, $30: 1-2$.

[2] Dick R.(ed), Steen E. (ed), and Detmer D. (ed) (1997). The Computer-Based Patient Record (Revised Edition) An Essential Technology for Health Care Committee on Improving the Patient Record Institute Of Medicine National Academy Press Washington, D.C.

[3] Silber D. (2003). European Commission, Information Society, eHealth Conference. Atlanta, Belgium www.openclinical.org/e-Health.html.

[4] Asangansi, I.E., Adejoro, O.O., Farri, O. \& Makinde, O. (2008). Computer use among doctors in Africa: Survey of trainees in a Nigerian teaching hospital. Journal of Health Informatics in Developing Countries, 2(1), 35-48.

[5] Majid, M. A. (2008). Electronic-health in Saudi Arabiajust around the corner? College of Public Health and Health Informatics, King Saud bin Abdul- Aziz, University for Health Sciences. Saudi Med J 2008; Vol. $29(2)$

[6] Vaquero L. M., Rodero-Merino L., Caceres J., Lindner M. (2008). A Break in the Clouds: Towards a Cloud Definition: ACM SIGCOMM Computer Communication Review Volume 39, 50-55.

[7] Zhang R., and Liu L. (2010). Security models and requirements for healthcare application clouds. In Proceedings of $3 \mathrm{rd}$ International Conference on Cloud Computing 2010. IEEE Cloud '10, Miami, Florida, USA, 268-275.

[8] Nagy, A. (2005). The Impact of E-Learning, in: Bruck, P.A.; Buchholz, A.; Karssen, Z.; Zerfass, A. (Eds). EContent: Technologies and Perspectives for the European Market. Berlin: Springer-Verlag, pp. 79-96.

[9] Piette J. D., Mendoza-Avelares, M. O., Ganser, M., Muhima, M., Marinec, N., \& Krishnan, S., (2011). A preliminary study of a cloud computing model for chronic illness self-care support in an underdeveloped country. Am. J. Prev. Med. 40:629-632.

[10] Rolim C.O., Koch F. L. \& Wetphall, C.B. (2010). A Cloud Computing Solution for Patient's Data Collection in Health Care Institutions. In proceeding of the Second International Conference on eHealth, Telemedicine, and Social Medicine (ETELEMED'10), St.Maarten, The Netherlands, pp.95-99.

[11] Koufi V, Malamateniou F. \& Vassilacopoulos G. (2010). Ubiquitous access to cloud emergency medical services. Proceedings of the 2010 10th IEEE International Conference on Information Technology and Applications in Biomedicine (ITAB); The 10th IEEE International Conference on Information Technology and Applications in Biomedicine Corfu, Greece. New York, NY: IEEE; 2010

[12] Abukhousa, E., Mohamed, N., \& Al-Jaroodi, J. (2012). eHealth Cloud: Opportunities and Challenges. Future Internet. 4, 621-645.

[13] Gottlieb, L.K., Stone, D., Dunbrack, L.A., \& Calladine, J. (2005). Regulatory and policy barriers to effective clinical data exchange: lessons learned from medsinfoED. Health Affairs, 24(5), 1197-1204Wood, s. (Ed).
(2008.) Introduction to Health Sciences Librarianship. New York: Haworth Press.

[14] Catteddu, D. \& Hogben, G. (2009): Cloud Computing: Benefits, risks and Recommendations for information security; European Network and Information Security Agency(ENISA);

https://www.enisa.europa.eu/act/rm/files/.../cloudcomputing.../fullReport

[15] Teng C., Mitchell, J. \& Walker, C. (2010). A Medical Image Archive Solution in the Cloud. In Proceedings of the2010 IEEE International Conference on Software Engineering and Service Sciences (ICSESS), Beijing, China, pp. 431-434.

[16] Rogers, E.M., The Diffusion of Innovations, 4th Edition, Free Press, New York, NY, 1995.

\section{Table 1. t-Test: Paired Two Sample for Means}

$$
\begin{array}{ll}
\text { ICT awareness } & \text { GHS can adopt } \\
\text { at the Hospital } & \text { all models }
\end{array}
$$

4

Variance

0.8813

0.8915

Observations

60

60

Pearson

Correlation

Hypothesized

Mean Difference

Df

t Stat

$\mathrm{P}(\mathrm{T}<=\mathrm{t})$ one-tail

t Critical one-tail 1.6710

$\mathrm{P}(\mathrm{T}<=\mathrm{t})$ two-tail 0.0386

t Critical two-tail 2.0010

Source: Field data, 2014 
Table 2. Correlation Matrix for Cloud Implementation by GHS.

\begin{tabular}{|c|c|c|c|c|c|c|}
\hline & & $\begin{array}{l}\text { Safe to store } \\
\text { data in cloud }\end{array}$ & $\begin{array}{l}\text { Cloud will } \\
\text { help improve } \\
\text { healthcare }\end{array}$ & $\begin{array}{l}\text { Hybrid } \\
\text { best } \\
\text { health }\end{array}$ & $\begin{array}{lr}\text { GHS } & \text { can } \\
\text { adopt } & \text { all } \\
\text { models } & \end{array}$ & $\begin{array}{l}\text { Encryption } \\
\text { used to } \\
\text { protect data }\end{array}$ \\
\hline \multirow{3}{*}{$\begin{array}{l}\text { Safe to store data in } \\
\text { cloud }\end{array}$} & Pearson Correlation & 1 & $.334^{* *}$ & $.343^{* *}$ & $.410^{* *}$ & .068 \\
\hline & Sig. (2-tailed) & & .009 & .007 & .001 & .604 \\
\hline & $N$ & 60 & 60 & 60 & 60 & 60 \\
\hline \multirow{3}{*}{$\begin{array}{l}\text { Cloud will help improve } \\
\text { healthcare }\end{array}$} & Pearson Correlation & $.334^{* *}$ & 1 & .136 & $.470^{* *}$ & -.007 \\
\hline & Sig. (2-tailed) & .009 & & .299 & .000 & .956 \\
\hline & $N$ & 60 & 60 & 60 & 60 & 60 \\
\hline \multirow{3}{*}{$\begin{array}{l}\text { Hybrid is best for } \\
\text { health }\end{array}$} & Pearson Correlation & $.343^{* *}$ & .136 & 1 & $.478^{* *}$ & .229 \\
\hline & Sig. (2-tailed) & .007 & .299 & & .000 & .078 \\
\hline & $N$ & 60 & 60 & 60 & 60 & 60 \\
\hline \multirow{3}{*}{$\begin{array}{l}\text { GHS can adopt all } \\
\text { models }\end{array}$} & Pearson Correlation & $.410^{* *}$ & $.470^{* *}$ & $.478^{* *}$ & 1 & .121 \\
\hline & Sig. (2-tailed) & .001 & .000 & .000 & & .356 \\
\hline & $N$ & 60 & 60 & 60 & 60 & 60 \\
\hline \multirow{3}{*}{$\begin{array}{l}\text { Encryption used to } \\
\text { protect data }\end{array}$} & Pearson Correlation & .068 & -.007 & .229 & .121 & 1 \\
\hline & Sig. (2-tailed) & .604 & .956 & .078 & .356 & \\
\hline & $N$ & 60 & 60 & 60 & 60 & 60 \\
\hline
\end{tabular}

**. Correlation is significant at the 0.01 level ( 2 tailed).

Source: Field data, 2014. 